\title{
Review of Self-Regulated Learning in Massive Open Online Course
}

\author{
Yongjin Zhu ${ }^{1,2^{*}} \quad$ Siti Maziha Mustapha $^{2} \quad$ Bo Gong $^{1}$ \\ 1.Department of Foreign Studies, Hubei Normal University, Huangshi 435002, China \\ 2.Faculty of Business, Information and Human Science, Infrastructure University Kuala Lumpur, Kajang 43000, \\ Malaysia \\ *E-mail of the corresponding author: yj.zhu@hbnu.edu.cn
}

The research is financed by Chinese Production and Research Project (Project ID: 201901297003); Hubei Provincial Department of Education's Research Project on Teaching Reform in Colleges and Universities (Project ID:2017376);Chinese University Students' Project on Innovation and Entrepreneurship Project ID:S201913256032);Hubei Normal University's Research Project on Teaching Reform (Project ID: 2019013).

\section{Abstract}

Over the last decade, much attention has been paid the effects of self-regulated learning (SRL) in massive open online courses (MOOCs). However, a systematic understanding of the topic is rather limited. This study drew a general outline of important factors affecting the SRL in MOOCs. The study summarizes two important SRL modes as the theoretical basis. Then, the study analyses the motivational, metacognitive and cognitive regulation strategies, and behavioural regulation strategies which affect SRL in MOOCs. Finally, suggestions for future research in MOOCs are offered.

Keywords: self-regulated learning, MOOCs, mode, SRL strategies

DOI: $10.7176 / \mathrm{JEP} / 11-8-02$

Publication date:March $31^{\text {st }} 2020$

\section{Introduction}

Massive Open Online Courses (MOOCs) are a rapidly growing mode of educational provision, holding the potential to open up access to world class teaching and educational resources beyond geographical and social boundaries. MOOCs have changed the traditional learning way by putting thousands of learners from different locations into an online space where learners could study at their preferred pace and learning styles (Johnson, Becker, Estrada, \& Freeman, 2014).The MOOCs reduce the interaction between students and teachers by platformbased approaches to learning. Thus, students face great challenges under this learning environment, because they may lack immediate support and feel lost or socially isolated (Cho, Shen, \& Laffey, 2010; Sun \& Rueda, 2012). This means that the individual learners have to organize their own learning, which requires them to monitor and adjust their behaviours and actions in relation to their specific learning context. In a MOOC, individuals must determine when, how and with what content and activities they engage (Milligan \& Littlejohn, 2014). SelfRegulated Learning is an important factor in determining students' success in MOOCs environments (Lee and Choi 2011; Barnard, Paton, \& Lan 2008). SRL was generally considered to have positive effects on MOOC learning after reviewing many empirical studies on SRL in MOOCs by Lee (2019). A number of MOOC learners have self-efficacy beliefs and employ several SRL strategies such as help seeking to achieve their goal in MOOCs. In a recent study, 6,335 MOOC learners reported high self-efficacy and employed more SRL like effort regulation strategy to succeed in a MOOC (Alario-Hoyos et al 2017; Kizilcec et al, 2016). Thus, students in the MOOCs environment must engage in self-regulated learning behaviours more frequently. This study presents a systematic review of SRL in MOOCs.

\section{Definition of self-regulated learning}

Self-regulated learning includes metacognitive, motivational, and behavioural processes that are personally initiated to acquire knowledge. A self-regulated learning perspective shifts the focus of educational analyses from students' learning abilities and instructional environments as fixed entities to students' self-initiated processes for improving their methods and environments for learning (Zimmerman, 2015). Self-regulated Learners can be defined as students who are proactive in their efforts to learn because they are aware of their strengths and limitations and they are guided by personally set goals and task-related strategies (Zimmerman, 2002). These learners monitor their behaviours and self-reflect on their achievements. This enhances their motivation to continue to improve their strategies. Because of their superior motivation and adaptive learning methods, self-regulated students are not only more likely to succeed academically but to view their futures optimistically.

\section{Self-regulated learning modes}

The research of self-regulated learning is extensive in nature and scope, and consequently has led to the development of several models and theories attempting to describe and distinguish attributes of successful learners 
(Bandura, 1986; Boekaerts et al., 2000; Pintrich, 2000; Zimmerman, 1990). Even many theories have been used to analyse the self-regulated learning, two major modes are popularly accepted by the many scholars.

\subsection{Zimmerman' Cyclical self-regulated learning mode}

Zimmerman (2000) defines self-regulation as "self-generated thoughts, feelings, and actions that are planned and cyclically adapted to the attainment of personal goals". Zimmerman's model (see Figure 1) holds there are three phases in the process of self-regulated learning: (1) the forethought phase, (2) the performance phase, and (3) the self-reflection phase. Each of these phases in turn reflects specific components: (1) Meta-cognitive, (2) Motivational, and (3) Behavioral (Zimmerman, 2002), in which the learner undertakes particular processes in order to self-regulate. During the forethought phase, the students analyse the tasks, set goals for action, plan how to achieve them and a lot of motivational beliefs are built and influence the activation of learning strategies. In the performance phase, the students actually execute the task, while they monitor how they are progressing, and apply a lot of strategies to keep themselves cognitively engaged and motivated to finish the task. Lastly, in the selfreflection phase, students assess how they have performed the task, making attributions about their success or failure. These attributions generate self-reactions that can positively or negatively influence how the students approach the task in later performances.

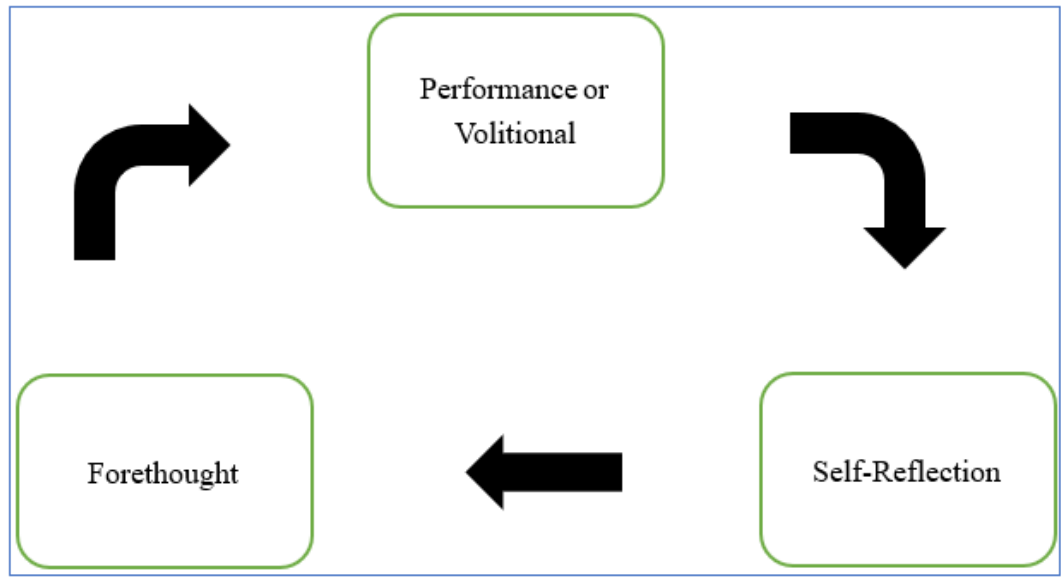

Figure 1. Cyclical Self-regulated Learning Mode (Zimmerman, 2000)

\subsection{Pintrich's component-oriented SRL model}

Pintrich (2000) defined SRL is as "an active, constructive process whereby learners set goals for their learning and then attempt to monitor, regulate, and control their cognition, motivation, and behaviour, guided and constrained by their goals and the contextual features in the environment (p.451).

Pintrich (2000) proposes four phases and four components, that in-turn lead to several self-regulation processes (see Table1). The self-regulatory processes have four phases: (1) planning and activation, (2) monitoring, (3) control and (4) reaction and reflection. These phases are then equally overlapped by four components: (1) cognition, (2) motivation, (3) behaviour and (4) context, under which interactions are produced as learners' progress and employ particular self-regulating processes accordingly to complete a set learning task. 
Table 1. Pintrich's component-oriented SRL model

\begin{tabular}{|c|c|c|c|c|}
\hline \multicolumn{5}{|c|}{ Areas for Regulation } \\
\hline Phrase & Cognition & Motivation/Affect & Behaviour & Context \\
\hline $\begin{array}{l}\text { 1.Forethought } \\
\text { Planning and } \\
\text { activation }\end{array}$ & Target goal setting & $\begin{array}{l}\text { Goal orientation } \\
\text { adoption } \\
\text { Efficacy judgement }\end{array}$ & $\begin{array}{lr}\text { Time and effect } \\
\text { planning } \\
\text { Planning for self- } \\
\text { observations } \\
\text { behaviour }\end{array}$ & $\begin{array}{l}\text { Perceptions of } \\
\text { task } \\
\text { Perceptions of } \\
\text { content }\end{array}$ \\
\hline 2.Monitoring & $\begin{array}{l}\text { Metacognitive } \\
\text { awareness } \\
\text { monitoring } \\
\text { cognition, }\end{array}$ & $\begin{array}{l}\text { Awareness and } \\
\text { monitoring of } \\
\text { motivation and affect }\end{array}$ & $\begin{array}{l}\text { Awareness and } \\
\text { monitoring of effort, } \\
\text { time use, need for help } \\
\text { Self-observation of } \\
\text { behaviour }\end{array}$ & $\begin{array}{l}\text { Monitoring } \\
\text { changing task } \\
\text { and context } \\
\text { conditions }\end{array}$ \\
\hline 3.Control & $\begin{array}{lr}\text { Selection } & \text { and } \\
\text { adaption } & \text { of } \\
\text { cognitive } & \text { strategies } \\
\text { for learning thinking }\end{array}$ & $\begin{array}{l}\text { Selection and adaption } \\
\text { of strategies for } \\
\text { managing motivation } \\
\text { and affect }\end{array}$ & $\begin{array}{l}\text { Increase/decrease } \\
\text { effort } \\
\text { persist, give up } \\
\text { Help-seeking } \\
\text { behaviour }\end{array}$ & $\begin{array}{l}\text { Change or } \\
\text { renegotiate task } \\
\text { Change or leave } \\
\text { context }\end{array}$ \\
\hline $\begin{array}{l}\text { 4. Reaction and } \\
\text { reflection }\end{array}$ & $\begin{array}{l}\text { Cognitive } \\
\text { judgements } \\
\text { Attributions }\end{array}$ & $\begin{array}{l}\text { Affective reactions } \\
\text { Attributions }\end{array}$ & Choice behaviour & $\begin{array}{l}\text { Evaluation } \\
\text { task } \\
\text { Evaluation } \\
\text { context }\end{array}$ \\
\hline
\end{tabular}

\section{Motivational regulation strategies: self-efficacy and achievement motivation}

Self-Efficacy (SE) is a major component and refers to an individual's judgement of their capabilities to organize and execute courses of action required to achieve desired performances (Bandura, 1997). Most studies have showed that most learners had high self-efficacy (Mustapha, S.M. 2011). Littlejohn (2016) found that participants who were working as data professionals had high self-efficacy scores in the Self-Regulated Learning at Work Questionnaire (SRLWQ). According to Morales Chan and Hernandez (2015), all participants showed high selfefficacy levels in the Motivated Strategies for Learning Questionnaire (MSLQ) in their SRL profiles. Some studies provided evidence that self-efficacy was highly connected to familiarity with the task (Zimmerman, 2000b). The research by Littlejohn et al. (2016) recorded that high self-efficacy scores particularly related to previous exposure to MOOC content. Hood (2015) also found that there were significant differences in self-efficacy between learners who were data professionals and those who were not in SRLWQ in a MOOC on teaching data science. Besides, the results revealed that familiarity with MOOC platforms was also related to high levels of self-efficacy (Littlejohn et al., 2016). This was explained by the concept of online technologies self-efficacy, which has been actively examined in traditional online learning. Furthermore, self-efficacy for English was found as a new form of self-efficacy. Liang-Yi (2015) explored the effectiveness of self-regulated learning in MOOCs on non-native English speakers. The study suggested that English self-efficacy was a defining element affecting this language application. And there was a positive and significant correlation between non-English learners' self-efficacy and self-regulated learning in MOOCs. The students with higher level of English self-efficacy made better use of selfregulated learning strategies under MOOCs environments. Therefore, the results of Liang-Yi's study suggested that the self-efficacy for English was one of the unique features of learners in MOOCs.

The achievement goal theory means that learners have differing goals or differing reasons for engaging or not engaging in learning activities; students also have differing standards for evaluating the outcomes of learning activities (Patrick et al., 2011). The goal theory was started from two goal perspectives: Mastery goals and performance goals. Later, Elliot and Church (1997) proposed a trichotomous theory, three types of goal orientations were identified: mastery, performance approach, and performance-avoidance. After that, Elliot and McGregor (2001) made further distinctions, and proposed four categories: performance approach, performance avoidance, mastery approach, and mastery avoidance. Students who desired to improve his competence by way of learning, deepening understanding, and enhancements are considered to be a mastery approach orientation. Students who were afraid of failure, anxious, and focused on surpassing their previous achievements are considered a mastery-avoidance goal orientation. Students with a performance-approach goal orientation are focused on the demonstration of competence relative to others by trying to outperform relevant others. Conversely, students with a performance-avoidance goal orientation are focused on avoiding looking incompetent and being outperformed by others (Elliot, 2005).

Many studies have revealed that the mastery and performance approach had positive relationship with the SRL learning and academic achievements, while the mastery and performance avoidance goal orientation were 
negatively related with the SRL and academic achievement. In some circumstances, the there was no significant relationships found between mastery and performance avoidance goal orientation and academic achievements. Ertuğrul Şahin (2016) found that there was no significant difference between male and female students in achievement goal orientation dimensions; however, the older students' mastery and performance approach orientations were significantly lower than younger students, which is inconsistent with Guan et al. (2006) who reported no difference in achievement goal orientations with age. Neroni, J, et, al (2018) studied 1128 distance university students in Netherlands and found that goal orientation to be a positive predictor of academic performance, whereas performance avoidance and work avoidance were negative predictors of academic performance. There was non-significant relationship between mastery approach as well as for mastery avoidance and academic performance. Ying Zhou(2019) studied the effect of SRL learning strategies and goal orientation on Chinese students' academic achievements. The study revealed that mastery approach was positively correlated with the use of time-management strategies, thereby positively impacting the student's course achievement. Further, the performance-approach goal orientation had a positive indirect influence on academic performance, with the effort-regulation strategy fully mediating this relationship. Alhadabi, A. (2020) explored the relationship between grit, self-efficacy, achievement orientation goals, and academic performance of 258 American university students. The study revealed that the mastery approach goals were positively related with academic performance, while the avoidance goals had negative relationship with academic performance.

\section{Cognitive and metacognitive regulation strategies}

Cognitive regulation strategies consist of rehearsal, elaboration, organization, and critical thinking which were wildly used in traditional learning environments. However, task strategy, goal setting, and self-evaluation as a cognitive regulation strategy, were examined in many studies under the MOOCs (Hood et al., 2015; Littlejohn et al., 2016; Jansen, R. S.,2017; Lee, D.,2019). Task strategy means that learners employ different tasks, projects, activities and exams to realize their aims; Goal setting refers to setting task-specific goals that can provide guidance for cognition and metacognition; Self-evaluation refers to learner's ability to determine the development needed and the progress made. Littlejohn et al. (2016) discovered that high SRL level learners were inclined to employ more task strategies to achieve their aims than low SRL learners. Hood et al. (2015) found that learners who identified as data professionals had higher scores in task strategy in SRLWQ than those who took a MOOC for higher education qualifications; Kizilcec, R. F. (2017) investigated SRL in a sample of 4,831 learners across six MOOCs. Results indicated the SRL had significant relationship with academic achievement and the most pronounced SRL strategies were self-evaluation and elaboration, followed by strategic planning, task strategies, and goal setting; the least strategy was help seeking. In a summary, it is suggested that MOOC instructors or designers should also provide support for cognitive and metacognitive regulation processes based on the fact that MOOC learners used task strategies such as changing their approach to learning, taking notes, and setting goals.

\section{Behavioural and contextual regulation strategies: help seeking, time management, environment structing and effort regulation}

Behavioural and contextual regulation strategies in recent studies of MOOCs refer to help seeking, time management, environment structuring, and effort regulation strategy. Help Seeking relates to obtaining assistance from instructors with the aim of overcoming academic challenges (Richardson et al., 2012); Time Management refers to the ability to organize the time for study (Effeney, Carroll, \& Bahr, 2013); Environment Structuring means that learners have an advantage with the flexibility of time and place to prepare and study for their courses in MOOC; Effort regulation also called persistence refers to the capacity to persist when confronted with academic challenges (Richardson et al., 2012). Many researchers had tested the SRL strategies in MOOCs. Zheng, C (2018) employed Online Self-regulated Learning Questionnaire (SOL-Q) developed by Barnard (2009) to explore the students' SRL in English online course. The finding revealed that six SRL strategies in the research: goal setting, time management, environment structuring, help seeking, task strategies, and self-evaluation. Among these strategies, environment structuring, help seeking and task strategies were widely used by students. The study also proved that learners' promotional instrumentality played the most powerful role in positively predicting learners' online self-regulation and environment structuring; Help seeking was the strategy students employed the most in their learning process, while the time management is a vital element affecting MOOC learning. The results in Nawrot and Doucet's (2014) research showed that poor time management was the main cause of dropping out of a MOOC. Besides, the findings of the study by Onah and Sinclair (2016) revealed that undergraduate students had low-level of time management scores in a blended MOOC, showing mean scores of 2.95, which are supported by several MOOC study findings that factor with time were one of the major reasons for disengaging from MOOCs (Kizilcec \& Halawa, 2015); Effort regulation was also important factors affecting the learning in MOOC. Jansen, R. S,(2017) studied the students in MOOCs and tested the validity of traditional instruments Online Self-regulated Learning Questionnaire (SOL-Q) by Barnard, L.(2009) with the method of EFA and CFA analysis. The results revealed that metacognitive skills, environmental structuring, help seeking, time management, while persistence 
strategy were the major SRL strategies which were inconsistent with the Barnard' finding. Persistence strategy was one of the special effort regulations in MOOC which had not been minded previously. While conclusions cannot be drawn from this single study, effort regulation strategy could be important in MOOC learning in other findings that effort regulation strategy was positively correlated with improvement of academic achievement in regular online learning settings (Broadbent \& Poon, 2015). Learners are likely to complete a course and succeed in MOOCs if they are able to persist when they face distractions such as watching lecture videos for long time and undertaking uninteresting tasks.

\section{Conclusion}

This systematic review describes the current state of research on SRL in MOOCs. This study has attempted to summarize Zimmerman' cyclical self-regulated learning mode and Pintrich's component-oriented mode as the theoretical models of self-regulated learning which have been accepted by many researchers. The present review confirmed the vital influence of SRL in MOOCs. It was revealed that SRL positively affected MOOC learning and learners used SRL strategies in MOOCs. Self-efficacy and achievement motivation have been proven as the motivational factors affecting SRL in MOOCs. Goal setting, task strategy, and self-evaluation were identified as metacognitive and cognitive regulation strategy in these studies. Help seeking, time management, environment structuring and effort regulation strategy were identified as behavioural regulation strategies. The results of SRL in MOOCs were different from those of SRL in traditional learning context due to the unique characteristics of MOOCs. Findings of this review could offer potential new insights for future research on MOOCs. Furthermore, this study could give researchers new information about learners' SRL behaviours and the importance of supporting SRL in MOOCs.

Based on the findings of this review, directions for future research are provided. The MOOCs is totally different from the traditional learning, while the previous studies explored the strategies in MOOCs with the instruments invented for the traditional contexts. Due to this, some unique learning methods in MOOCs may be ignored and should be researched in the future. Furthermore, the scope of our study was intentionally limited to top educational research journals. Future study could cover a broader scope by including recent conferences, theses, and books to allow for further analysis of global trends in research on SRL in MOOCs; Lastly, SRL of different professionals in different contexts should also be explored.

\section{References}

Alhadabi, A., \& Karpinski, A. C. (2020). Grit, self-efficacy, achievement orientation goals, and academic performance in University students. International Journal of Adolescence and Youth, 25(1), 519-535.

Alario-Hoyos, C., Estévez-Ayres, I., Pérez-Sanagustín, M., Kloos, C. D., \& Fernández-Panadero, C. (2017).Understanding learners' motivation and learning strategies in MOOCs. The International Review of Research in Open and Distributed Learning, 18(3),119-137.

Barnard, L., Lan, W. Y., To, Y. M., Paton, V. O., \& Lai, S.-L. (2009). Measuring self-regulation in online and blended learning environments. The Internet and Higher Education, 12(1), 1-6.

Bandura, A. (1997).Self-efficacy: The exercise of control. New York: W. H. Freeman and Company.

Bandura, A. (1986). Social foundations of thought and action: A social cognitive theory. Englewood Cliffs, NJ: Prentice- Hall, Inc.

Boekaerts, M., \& Niemivirta, M. (2000). Self-regulated learning: Finding a balance between learning goals and ego-protective goals. In M. Boekaerts, P. R. Pintrich, \& M. Zeidner (Eds.), Handbook of self-regulation (p. 417-450). Academic Press.

Broadbent, J., \& Poon, W. L. (2015). Self-regulated learning strategies \& academic achievement in online higher education learning environments: A systematic review. The Internet and Higher Education, 27, 1-13.

Cho, M.-H., Demei, S., \& Laffey, J. (2010). Relationships Between Self-Regulation and Social Experiences in Asynchronous Online Learning Environments. Journal of Interactive Learning Research, 21(3), 297-316.

Effeney, G., Carroll, A., \& Bahr, N. (2013). Self-Regulated Learning: Key strategies and their sources in a sample of adolescent males. Australian Journal of Educational \& Developmental Psychology, 13,58-74.

Elliot, A. J., and Church, M. (1997). A hierarchical model of approach and avoidance achievement motivation. Pers. Soc. Psychol. 72, 218-232.

Elliot, A., \& McGregor, H. (2001). A $2 \times 2$ achievement goal framework. Journal of Personality and Social Psychology - PSP, 80, 501-519.

Elliot, A. J. (2005). "A conceptual history of the achievement goal construct," in Handbook of Competence and Motivation, eds A. J. Elliot and C. S. Dweck (New York, NY: Guilford Press), 52-72.

Ertuğrul Şahin, N. T., Recep Kürkçü. (2016). Sex and Age Differences in Achievement Goal Orientations in Turkish Adolescents. Journal of Education and Practice, 7(27), 149-156.

Guan, J., Xiang, P., McBride, R., \& Bruene, A. (2006). Achievement goals, social goals, and students' reported persistence and effort in high school physical education. Journal of Teaching in Physical Education, 25(1), 
$58-74$.

Jansen, R. S., van Leeuwen, A., Janssen, J., Kester, L., \& Kalz, M. (2017). Validation of the self-regulated online learning questionnaire. Journal of Computing in Higher Education, 29(1), 6-27.

Hood, N., Littlejohn, A., \& Milligan, C. (2015). Context counts: How learners' contexts influence learning in a MOOC. Computers \& Education, 91, 83-91.

Johnson, L., Adams Becker, S., Estrada, V., \& Freeman, A. (2014). NMC Horizon Report: 2014 K-12 Edition. Retrieved from Austin, Texas.

Kizilcec, R. F., Pérez-Sanagustín, M., \& Maldonado, J. J. (2016). Recommending Self-Regulated Learning Strategies Does Not Improve Performance in a MOOC. Paper presented at the Proceedings of the Third (2016) ACM Conference on Learning @ Scale, Edinburgh, Scotland, UK.

Lee, D., Watson, S., \& Watson, W. (2019). Systematic literature review on self-regulated learning in massive open online courses. Australasian Journal of Educational Technology, 35,28-41.

Lee, Y., \& Choi, J. (2011). A review of online course dropout research: implications for practice and future research. Educational Technology Research and Development, 59(5), 593-618.

Lee, D., Watson, S. L., \& Watson, W. R. (2020). The Relationships Between Self-Efficacy, Task Value, and SelfRegulated Learning Strategies in Massive Open Online Courses. The International Review of Research in Open and Distributed Learning, 21(1), 23-39.

Liang-Yi, C. (2015). Exploring the Effectiveness of Self-Regulated Learning in Massive Open Online Courses on Non-Native English Speakers. International Journal of Distance Education Technologies (IJDET), 13(3), 6173.

Littlejohn, A., Hood, N., Milligan, C., \& Mustain, P. (2016). Learning in MOOCs: Motivations and self-regulated learning in MOOCs. The Internet and Higher Education, 29, 40-48.

Milligan, C. and Littlejohn, A. (2014) Supporting professional learning in a massive open online course. International Review of Research in Open and Distance Learning 15 (5) 197-213.

Morales Chan, M., Hernandez Rizzardini, R., Barchino Plata, R., \& Amelio Medina, J. (2015). MOOC using cloud-based tools: A study of motivation and learning strategies in Latin America. International Journal of Engineering Education, 31(3), 901-911.

Mustapha, S.M. (2011) The relationship between self-efficacy and classroom participation among students in a tertiary institute (Unpublished Doctoral Thesis). Open Univesity Malaysia, Kuala Lumper, Malaysia.

Neroni, J., Meijs, C., Leontjevas, R., Kirschner, P. A., \& De Groot, R. H. M. (2018). Goal Orientation and Academic Performance in Adult Distance Education. The International Review of Research in Open and Distributed Learning, 19(2),192-208.

Nawrot, I., \& Doucet, A. (2014, April). Building engagement for MOOC students: Introducing support for time management on online learning platforms. Paper presented at the 23rd International World Wide Web Conference, Seoul, South Korea.

Onah, D. F. O, \& Sinclair, J. E. (2016, September). A multi-dimensional investigation of self-regulated learning in a blended classroom context: A case study on eLDa MOOC. In M. E. Auer, G. Guralnick, \& J. Uhomoibhi (Eds.), Proceedings of the 19th International Conference on Interactive Collaborative Learning . 63-85. Springer

Patrick, H., Kaplan, A., and Ryan, A. M. (2011). Positive classroom motivational environments: convergence between mastery goal structure and classroom social climate. J. Educ. Psychol. 103, 367-382.

Pintrich, P. R. (2000b). The role of goal orientation in self-regulated learning. In M. Boekaerts, P. R. Pintrich, \& M. Zeidner (Eds.), Handbook of self-regulation (pp. 451-502). San Diego, CA: Academic.

Richardson, M., Abraham, C., \& Bond, R. (2012). Psychological correlates of university students' academic performance: A systematic review and meta-analysis. Psychological Bulletin, 138, 353-387.

Sun, J. C.-Y., \& Rueda, R. (2011). Situational interest, computer self-efficacy and self-regulation: Their impact on student engagement in distance education. British Journal of Educational Technology, 43, 191-204.

Jansen, R. S., van Leeuwen, A., Janssen, J., Kester, L., \& Kalz, M. (2017). Validation of the self-regulated online learning questionnaire. Journal of Computing in Higher Education, 29(1), 6-27.

Zheng, C., Liang, J.-C., Li, M., \& Tsai, C.-C. (2018). The relationship between English language learners' motivation and online self-regulation: A structural equation modelling approach. System, 76, 144-157.

Zhou, Y., \& Wang, J. (2019). Goal orientation, learning strategies, and academic performance in adult distance learning. Social Behavior and Personality, 47(7), 1-20.

Zimmerman, B. J. (1990). Self-Regulated Learning and Academic Achievement: An Overview. Educational Psychologist, 25(1), 3-17.

Zimmerman B. J., (2002). Becoming a Self-Regulated Learner: An Overview, Theory Into Practice, vol. 41, no. 2, pp. 64-70.

Zimmerman, B. J. (2015). Self-Regulated Learning: Theories, Measures, and Outcomes. In J. D. Wright (Ed.), International Encyclopedia of the Social \& Behavioral Sciences (Second Edition). Oxford: Elsevier, 541-546. 